\title{
PELATIHAN TEKNIK MENYUSUN LAPORAN KEUANGAN UNTUK UMKM AGRIBISNIS
}

\author{
Mais Ilsan', Muhammad Salim², Tsalis Kurniawan Husain ${ }^{3}$ \\ ${ }_{1}$ Universitas Muslim Indonesia, Makassar \\ email: mais.ilsan.umi@gmail.com \\ ${ }^{2}$ Universitas Muslim Indonesia, Makassar \\ email: muh.salim15@yahoo.com \\ ${ }^{3}$ Universitas Muslim Indonesia, Makassar \\ korespondensi email: tsalis.kurniawan@umi.ac.id
}

\begin{abstract}
The goal to be achieved in this service program is to help compile and make financial statements CV. Kasih dan Sayang. Specific targets to be completed are knowledge and skills in preparing and formatting financial statements. The problem in preparing financial statements is knowledge and skills in the recording of business finances. Therefore, the challenges in this target group need to be overcome by increasing knowledge and training in making financial statements that are easy and helping financial records for partners. The method that will be used in this service program is participation method. CV. Kasih dan Sayang were given financial statement training. The results of this community service activity are trainees who are able to provide training materials that are supported by using financial statements formats in the form of MS. Excel is in accordance with the case of business transactions. In addition, the financial statement format is in the form of an MS. Excel will tidy up and make it easier to make business financial statements.
\end{abstract}

Keywords: cokelat makalate; financial statements; MSME

\begin{abstract}
ABSTRAK
Tujuan yang ingin dicapai dalam program pengabdian ini adalah untuk membantu menyusun dan membuat laporan keuangan CV. Kasih dan Sayang. Target khusus yang ingin dicapai adalah meningkatnya pengetahuan dan keterampilan dalam menyusun dan membuat format laporan keuangan. Permasalahan dalam membuat laporan keuangan adalah kurangnya pegetahuan dan keterampilan dalam pencatatan keuangan usaha. Oleh karena itu, permasalahan pada kelompok sasaran ini perlu diatasi dengan peningkatan pengetahuan dan keterampilan melalui pelatihan pembuatan laporan keuangan yang mudah dan membantu pencatatan keuangan bagi mitra. Metode yang akan dipakai dalam program pengabdian ini adalah metode partisipasi. Pihak UMKM CV. Kasih dan Sayang diberikan pelatihan laporan keuangan. Hasil kegiatan pengabdian ini adalah peserta pelatihan mampu menerapkan materi pelatihan ditunjukkan dengan kemampuan dalam menggunakan format laporan keuangan dalam bentuk MS. Excel sesuai dengan kasus transaksi usaha. Selain itu, format laporan keuangan dalam bentuk aplikasi MS. Excel akan lebih merapikan dan memudahkan dalam pengoperasian dalam pembuatan laporan keuangan usaha.
\end{abstract}

Kata Kunci: cokelat makalate; laporan keuangan; UMKM agribisnis 


\section{PENDAHULUAN}

Perekonomian nasional Indonesia akan memiliki pondasi yang kuat jika UMKM telah menjadi aktor utama ekonomi yang produktif dan memiliki daya saing. UMKM kecenderungannya berbasis pada sumber daya ekonomi lokal dan biasanya tidak bergantung pada bahan baku impor (Hatneny et al., 2019) (Rizal et al., 2019). Salah satu UMKM yang mengelola komoditas lokal menjadi produk yang bernilai tinggi adalah CV. Kasih dan Sayang. UMKM ini didirikan oleh oleh Bapak Irwan dan adiknya Ibu Hariati sejak tahun 2008 dengan Surat izin dari Walikota Makassar Nomor: 503/0197/SIU/PKB/08/KPAP tentang surat izin perdagangan kecil. CV. Kasih dan Sayang berlokasi di Jalan sungai saddang baru lorong berkah No 40 A Makassar. Dengan luas lahan $144 \mathrm{~m} 2$, UMKM ini adalah salah satu perusahaan yang bergerak dalam bidang agribisnis, yaitu dalam bidang pengolahan bubuk kakao untuk dijadikan produk yang mempunyai nilai ekonomi.

Bahan baku yang digunakan dalam usaha ini adalah kakao yang berasal dari sulawesi, bekasi dan tangerang. Industri ini mampu menghasilkan kurang lebih 1.000 bungkus cokelat dalam 1 bulan. Adapun nama merek yang digunakan adalah Cokelat Makalate. Usaha yang telah berdiri sejak 10 tahun yang lalu ini tentunya telah melakukan banyak perbaikan. Pengembangan produk cokelat selalu dilakukan inovasi untuk mengikuti selera pasar namun tetap mempertahankan rasa khas, yaitu rasa khas cokelat dengan sedikit gula atau tanpa gula. Produk yang diposisikan sebagai produk oleh-oleh khas Makassar ini masih memliki kelemahan karena bukan menjadi produk top of mind untuk kategori produk oleh-oleh khas Makassar (Husain \& Amran, 2019).

CV. Kasih dan Sayang tentunya masih memiliki beberapa kelemahan dalam manajemen usahanya, diantaranya perekrutan karyawan tidak dilakukan secara professional, hal ini terlihat dari tidak adanya syarat dan rangkaian proses perekrutan tenaga kerja. Oleh karena itu, karyawan cenderung tidak memiliki keterampilan dan pengetahuan tentang tugasnya masing-masing, akhirnya hanya belajar secara otodidak. Keadaan ini tentunya akan membuat usaha tidak berjalan secara efektif.

Uraian situasi usaha menggambarkan kurangnya keterampilan karyawan CV. Kasih dan Sayang. Hal ini juga berlaku untuk bagian keuangan yang belum optimal dalam menciptakan laporan keuangan sesuai standar. Keadaan ini sejalan dengan penelitian Komaludin \& Wahid (2018) menunjukkan bahwa kemampuan dan keterampilan dalam menyusun laporan keuangan yang dimiliki pelaku UKM relatif rendah disebabkan karena kurangnya pengetahuan dan pelatihan dasar akuntansi. Kondisi ini berdampak pada sulitnya UMKM untuk mengakses permodalan untuk meningkatkan kinerja usahanya. Dalam jangka panjang akan menjadi kelemahan dan faktor penghambat majunya suatu usaha (Kusumaastuti \& Asih, 2015) (Kautsar et al., 2016) (Machmud \& Huda, 2011). Keperluan laporan keuangan, selain memudahkan akses permodalan, juga sebagai salah satu alat utama dalam mengukur kinerja usaha yang dijalankan. 
Berdasarkan uraian di atas maka yang menjadi permasalahan CV. Kasih dan Sayang: adalah kurangnya pengetahuan dan keterampilan dalam menyusun laporan keuangan serta belum memiliki laporan keuangan yang sifatnya bankable.

\section{METODE PELAKSANAAN}

Metode pendekatan yang digunakan untuk mendukung realisasi program ini adalah metode partisipatif. Menurut Mustanir et al. (2019) metode partisipatif ini adalah metode pendampiangan yang bertujuan untuk memberdayakan kelompok masyarakat atau kelompok mitra dalam menyelesaikan permasalahannya. Metode ini melibatkan secara langsung UMKM CV. Kasih dan Sayang sebagai produsen cokelat makalate untuk meningkatkan pengetahuan dan keterampilan mereka, yaitu melalui: 1) Brainstorming, 2) Pelatihan pembuatan laporan keuangan.

Berdasarkan uraian tersebut, maka kegiatan program yang dilakukan adalah sebagai berikut: (1) Tahap Pertama: Melakukan brainstorming tentang pentingnya membuat laporan keuangan. Partisipasi UMKM: CV. Kasih dan Sayang mendiskusikan hambatan-hambatan selama ini dalam membuat laporan keuangan. (2) Tahap Kedua: Membantu CV. Kasih dan Sayang dalam membuat laporan keuangan usaha, termasuk pelatihan singkat akuntansi dasar untuk membantu memahami laporan keuangan. Partisipasi UMKM: CV. Kasih dan Sayang mempraktekkan cara membuat laporan keuangan. (3) Tahap Ketiga: Melakukan monitoring dan evaluasi pada seluruh kegiatan secara bertahap. Kegiatan ini bertujuan untuk mengetahui tingkat pemahaman dan penerapan tentang materi yang telah diberikan, serta permasalahan yang dihadapi dalam pelaksanaan kegiatan. Partisipasi UMKM: CV. Kasih dan Sayang melaporkan semua kendala dan permasalahan yang mereka alami dan bersama-sama dengan tim pelaksana program mencari solusinya.

\section{HASIL DAN PEMBAHASAN}

Peserta dalam kegiatan ini adalah 1 mitra usaha berupa UMKM yang bergerak di bidang agribisnis hilir, yaitu CV. Kasih dan Sayang. Pada kegiatan pengabdian, tim pelaksana memberi pelatihan kepada salah satu karyawati yang bertanggung jawab pada bagian keuangan usaha. Bentuk kegiatan dilaksanakan dengan tiga tahapan yaitu tahapan brainstorming, pemberian materi akuntansi dasar, dan pembuatan format laporan keuangan.

Tahap pertama yakni melakukan brainstorming tentang pentingnya membuat laporan keuangan Pada tahapan ini, tim pelaksana dan CV. Kasih dan Sayang mendiskusikan hambatan-hambatan selama ini dalam membuat laporan keuangan. Dari hasil diskusi ditemukan fakta bahwa dalam perekrutan karyawan tidak pernah diberikan training dalam pembuatan laporan keuangan, sehingga karyawan yang ditugaskan pada bagian keuangan hanya melakukan secara otodidak. Kelemahan ini sejalan dengan penelitian Puspitaningrum D.K et al., (2017) yang menjelaskan bahwa pelaku UMKM 
tidak menguasai serta tidak menerapkan sistem keuangan yang memadai. Beberapa dari UMKM tersebut juga tidak atau belum mempunyai serta menerapkan pencatatan akuntansi secara ketat dan disiplin dengan pembukuan yang teratur dan sistematis.

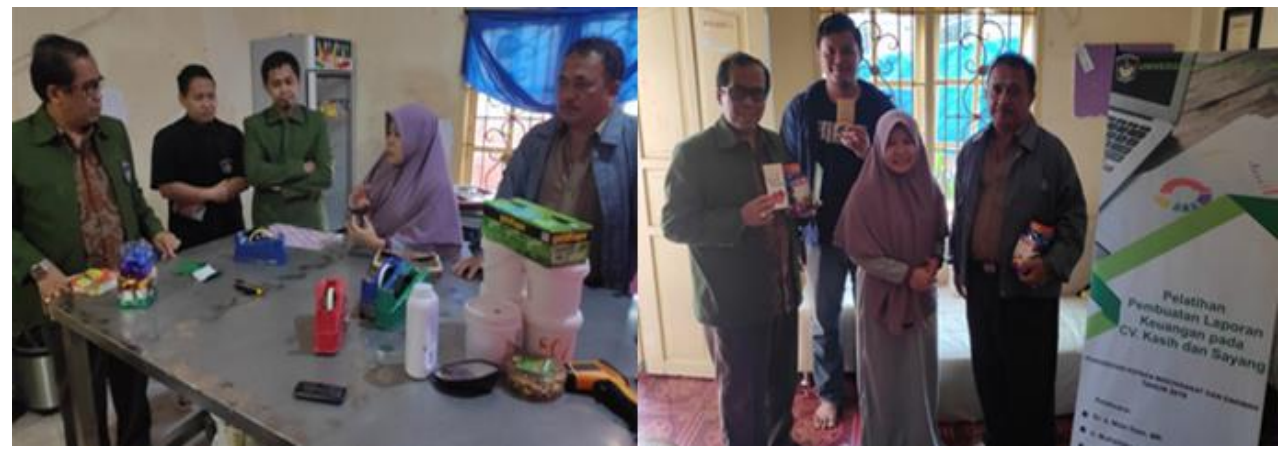

Gambar 1. Observasi dan brainstorming dengan pihak CV. Kasih dan Sayang

Tahap kedua yakni memberi materi tentang akuntansi dasar. Pada tahapan ini Tim Pelaksana menghadirkan trainer akuntansi dari Bahana Consulting yang bernama Pak Sarjayadi yang sudah berpengalaman dalam training akuntansi sedangkan dari pihak CV. Kasih dan Sayang diwakili oleh saudari Nurlaela Saudin yang merupakan karyawati yang bertanggung jawab dalam bagian keuangan usaha. Tahapan ini bermanfaat untuk memberi pemahaman dasar mengenai dasar teori akuntansi kepada pihak mitra agar memudahkan menggunakan aplikasi akuntansi di tahap berikutnya. Dalam pelaksanaan tahapan ini diharapkan mitra memahami laporan keuangan sebagai sumber informasi dan alat bantu dalam mengambil suatu keputusan, khususnya dalam memperoleh gambaran kondisi kinerja keuangan perusahaan baik dalam keadaan untung ataupun rugi. Melalui catatan yang baik dan dilakukan secara konsisten serta periodik akan sangat membantu mengingatkan pemilik usaha mengenai semua transaksi yang telah dilakukan perusahaan selama periode tertentu. Catatan mengenai transaksi tersebut yang merupakan sumber utama pembuatan laporan keuangan (Pratiwi, 2012).

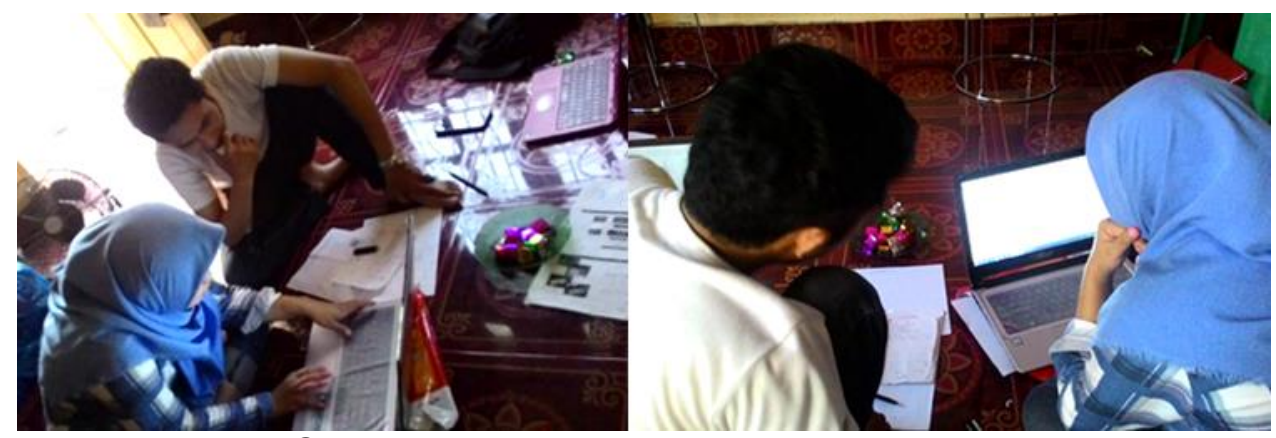

Gambar 2. Pemberian materi akuntansi dasar 
Tahap ketiga yakni pembuatan format laporan keuangan dalam aplikasi Ms. Excel. Pada tahapan ini, trainer membantu dalam membuat format laporan keuangan dalam bentuk Ms. Excel dan sekaligus memberi pelatihan penggunaan aplikasi tersebut sehingga memudahkan dalam pencatatan dan pembuatan laporan keuangan usaha. Tomasowa (2018) mengemukakan Aplikasi komputer Excel For Accounting merupakan salah satu media yang dapat digunakan untuk mempermudah, mempercepat dan menghasilkan laporan keuangan yang lebih akurat. Cukup satu kali membuat format maka setelah itu dengan menginput transaksi ke jurnal secara otomatis proses posting dan laporan keuangan langsung dihasilkan. Kemudahan ini tentu saja akan sangat membantu mengingat keterbatasan sumber daya manusia dan segala keterbatasan lainnya yang ada dalam menyusun laporan keuangan.

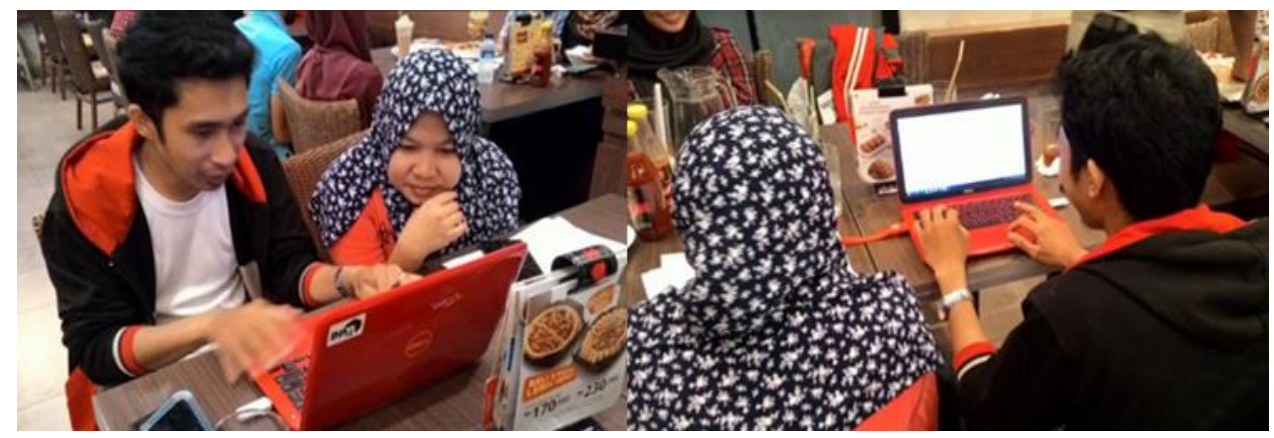

Gambar 3. Kegiatan pembuatan dan tutorial penggunaan format laporan keuangan

Pratiwi (2012) menambahkan fungsi Microsoft Excel yang dapat membantu dalam hal menghitung sampai pada kemampuannya dalam mempresentasikan data dalam bentuk informasi, maka hal ini dapat membantu juga dalam sistem akuntansi. Bahkan melaui Microsoft Excel, laporan keuangan dapat disusun secara sederhana dengan siklus yang lebih pendek yaitu dari penyusunan jurnal menjadi laporan keuangan sederhana.

Target luaran yang dicapai pada kegiatan pengabdian ini adalah meningkatnya pengetahuan dan keterampilan masyarakat dalam mengelola dan menyusun laporan keuangan pada mitra usaha. Hal ini ditunjukkan oleh kemampuan mitra usaha dalam membuat laporan keuangan sesuai dengan format laporan keuangan yang baru dengan studi kasus yang sesuai dengan kondisi keuangan usaha. Peningkatan keterampilan ini terlihat dari adanya perbandingan sebelum dan setelah diberi pelatihan. Adapun perbandingannya sebagai berikut: 


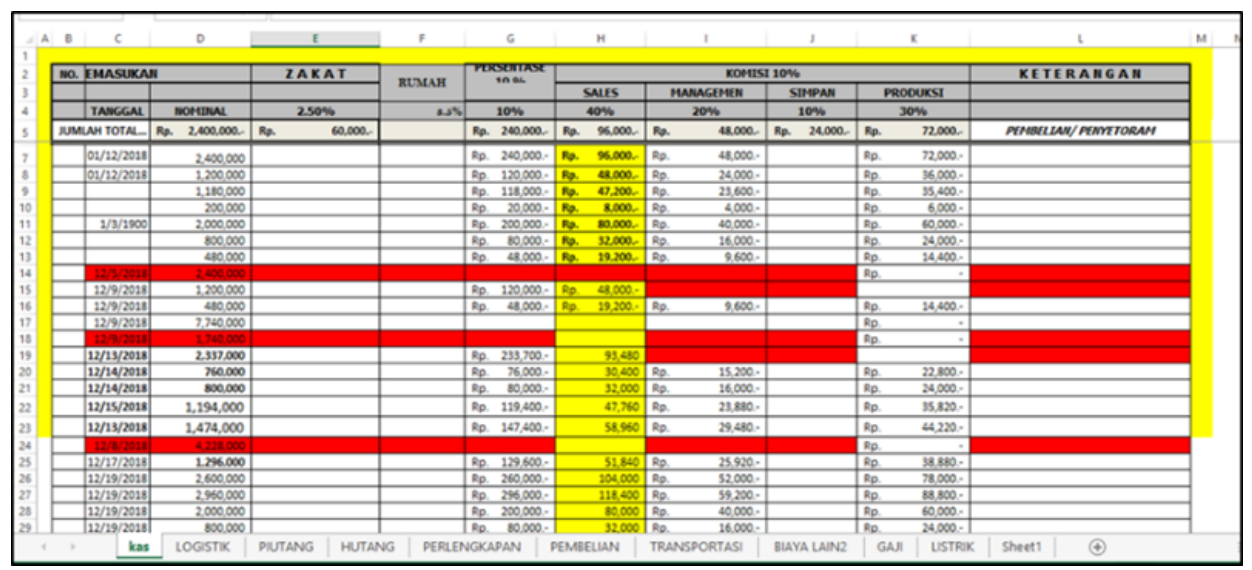

Gambar 4. Tampilan dashboard laporan keuangan sebelum pelatihan

Tampilan dashboard laporan keuangan pada gambar 4 masih terlihat sederhana, di mana yang menjadi dashboard utama hanya laporan kas ditunjang dengan subdashboard (logistic, piutang, hutang, dan seterusnya). Setelah dilakukan pelatihan dengan pencatatan transaksi yang sama dengan menggunakan format laporan keuangan yang baru, hasilnya dapat dilihat pada gambar 5 berikut.

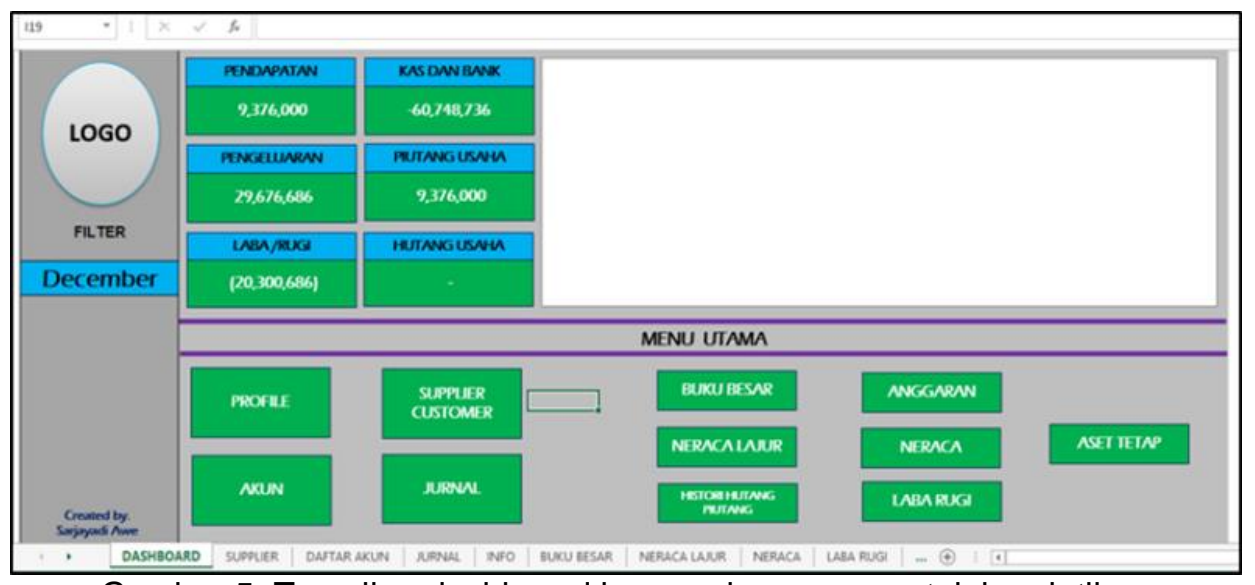

Gambar 5. Tampilan dashboard laporan keuangan setelah pelatihan

Pada dashboard setelah pelatihan terlihat jelas panel-panel laporan keuangan sehingga lebih memudahkan pembacaan kondisi keuangan usaha serta memudahkan dalam menginput setiap transaksi. Luaran lain dari kegiatan ini adalah format laporan keuangan usaha dalam bentuk Ms. Excel. Format laporan ini telah dirancang sedemikian rupa sehingga memudahkan pihak mitra usaha dalam mengoperasikannya. Adapun format laporan keuangan ditampilkan pada gambar-gambar berikut. 


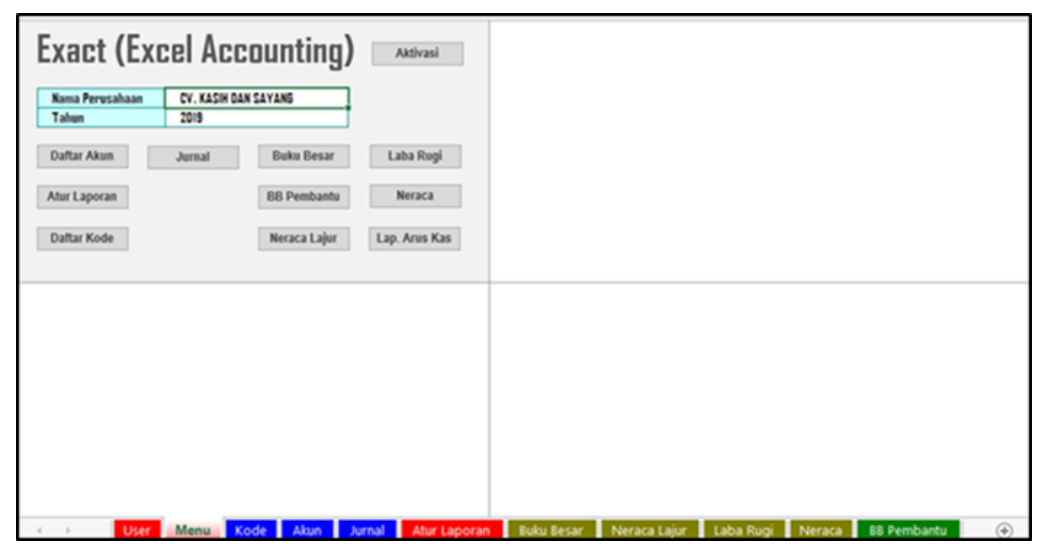

Gambar 6. Tampilan menu utama format laporan keuangan CV. Kasih dan Sayang dalam aplikasi MS. Excel

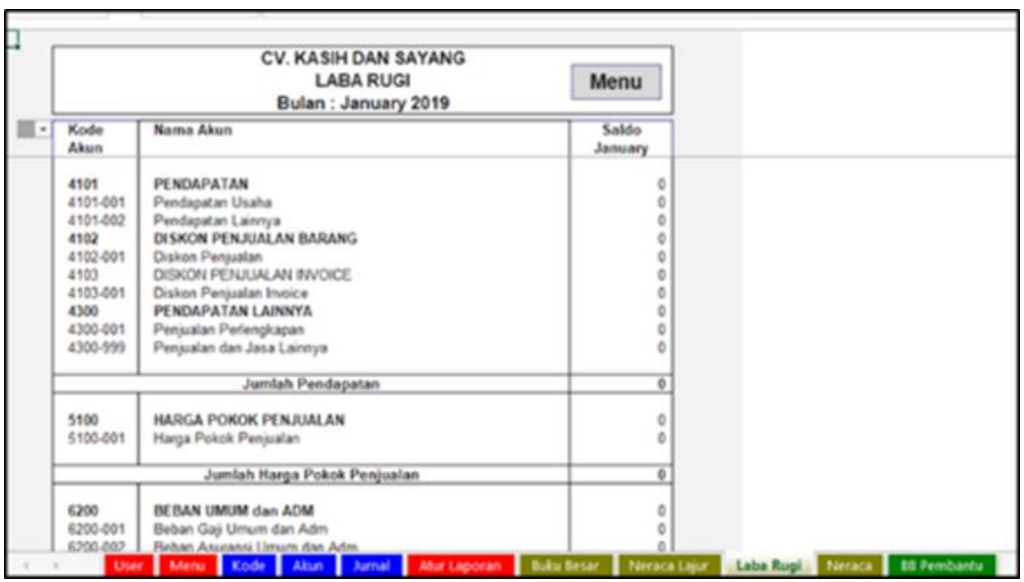

Gambar 7. Tampilan menu laporan rugi laba format laporan keuangan CV. Kasih dan Sayang dalam aplikasi MS. Excel

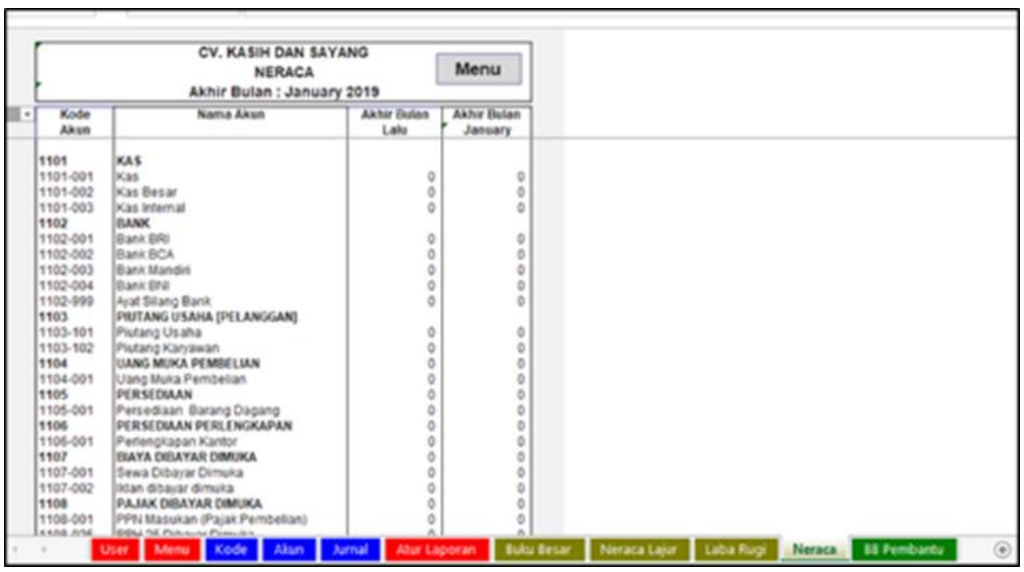

Gambar 8. Tampilan menu neraca format laporan keuangan CV. Kasih dan Sayang dalam aplikasi MS. Excel 


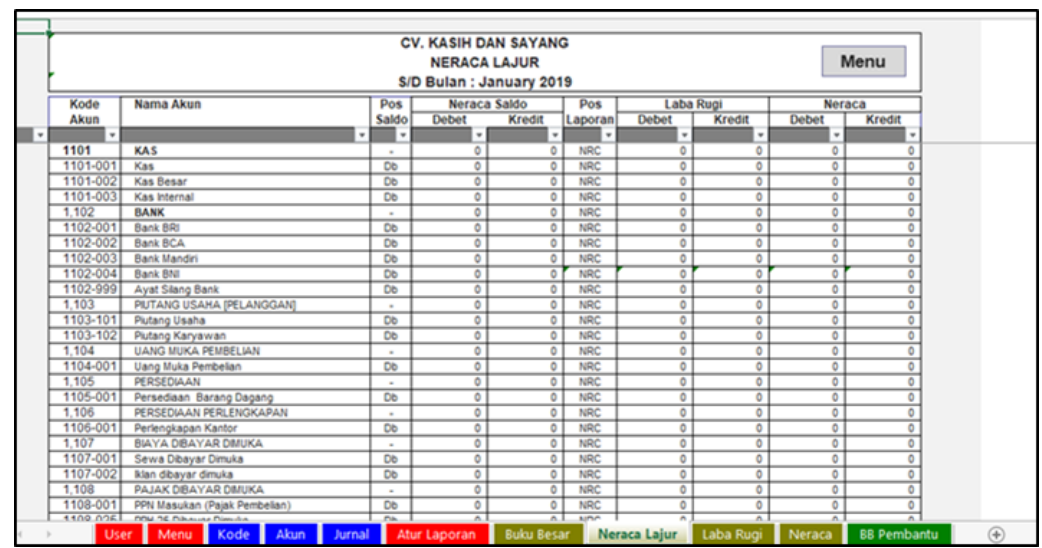

Gambar 9. Tampilan menu neraca format laporan keuangan CV. Kasih dan Sayang dalam aplikasi MS. Excel

Luaran kegiatan ini diharapkan mitra mampu menata dan mengelola laporan keuangannya dengan mudah, sistematis dan komputerisasi sehingga bisa membantu dalam pengambilan keputusan dalam rangka pengembangan usahanya.

\section{KESIMPULAN}

Berdasarkan hasil dari pelaksanaan pengabdian ini dapat disimpulkan bahwa masalah utama mitra dapat terjawab dan solusi telah ditentukan, yaitu pelatihan teknis menyusun laporan keuangan. Peserta pelatihan mampu menerapkan materi pelatihan ditunjukkan dengan kemampuan dalam menggunakan format laporan keuangan dalam bentuk MS. Excel sesuai dengan kasus transaksi usaha. Selain itu, format laporan keuangan dalam bentuk aplikasi MS. Excel akan lebih merapikan dan memudahkan dalam pengoperasian dalam pembuatan laporan keuangan usaha.

Mitra pengabdian harus melakukan training ketika merekrut karyawan yang akan ditempatkan pada bagian keuangan. Selain itu, jika usaha semakin berkembang disarankan untuk menggunakan aplikasi khusus dalam pencatatan laporan keuangan.

\section{DAFTAR RUJUKAN}

Hatneny, A. I., Mahardani, A. S., \& Saraswati, E. (2019). Pemberdayaan Masyarakat Pada UKM Depo Air Minum Tirta Barokah Dan Bakso Tuna Cintaku. Jurnal Inovasi Hasil Pengabdian Masyarakat (JIPEMAS), 2(1), 54-62. https://doi.org/10.33474/jipemas.v2i1.1604

Husain, T. K., \& Amran, F. D. (2019). Efektivitas pemasaran produk cokelat makalate melalui sms broadcast. Wiratani, 2(1), 52-66. http://jurnal.agribisnis.umi.ac.id/index.php/wiratani/article/view/35/0

Kautsar, I., Suroso, A. I., \& Hartrisari. (2016). Strategi Usaha Mikro dan Kecil Menghadapi Peluang dan Ancaman Pemberlakuan Masyarakat 
Ekonomi Asean (Studi Kasus Usaha Mikro dan Kecil Kota Depok). Jurnal Aplikasi Manajemen, 14(1), 126-139. https://doi.org/10.18202/jam23026332.14.1.14

Komaludin, A., \& Wahid, N. N. (2018). Analisis Kemampuan Menyusun Laporan Keuangan, Kemampuan Manajerial, Jiwa Kewirausahaan Dan Motivasi Sebagai Faktor Penentu Kinerja Operasional. Jurnal ASET (Akuntansi Riset), 10(1), 1-16. https://doi.org/10.17509/jaset.v10i1.7880

Kusumaastuti, P., \& Asih, E. M. (2015). Strategi Dan Langkah-Langkah Umkm Dalam Menghadapi Masyarakat Ekonomi Asean (MEA). Journal \& Proceeding FEB UNSOED, 5(1), 1-17. http://jp.feb.unsoed.ac.id/index.php/sca-1/article/viewFile/641/pdf_84

Machmud, Z., \& Huda, A. (2011). Chapter 9. SMEs' Access to Finance: An Indonesia Case Study. Small and Medium Enterprises (SMEs) Access to Finance in Selected East Asian Economies, 14(September), 261290. $\quad$ https://www.eria.org/uploads/media/Research-ProjectReport/RPR_FY2010_14_Chapter_9.pdf

Mustanir, A., Hamid, H., \& Syarifuddin, R. N. (2019). Pemberdayaan Kelompok Masyarakat Desa Dalam Perencanaan Metode Partisipatif. Moderat: Jurnal Ilmiah IImu Pemerintahan, 5(3), 227-239. https://doi.org/10.25147/MODERAT.V5I3.2677

Pratiwi, R. D. (2012). Menyusun Laporan Keuangan Sederhana Dengan Microsoft Excel. Media, 19(1), 64-70. http://publikasi.dinus.ac.id/index.php/media/article/view/896

Puspitaningrum D.K, T., Kurniawati, S. L., \& Metana, N. Y. (2017). Pelaporan Keuangan pada UMKM di Surabaya ( Studi Pada UKM Diah Cookies ). Jurnal Ilmiah Akuntansi Dan Bisnis, 2(1), 17-32. http://journal.undiknas.ac.id/index.php/akuntansi/article/view/164

Rizal, M., Mustapita, A. F., \& Kartika Sari, A. F. (2019). Pelatihan Untuk Pengajuan Pembiayaan Mudharabah Perbankan Syariah Sebagai Peningkatan Kinerja UMKM. Jurnal Inovasi Hasil Pengabdian Masyarakat (JIPEMAS), 3(1), 15-22. https://doi.org/10.33474/jipemas.v3i1.2569

Tomasowa, T. E. D. (2018). Aplikasi Excel for Accounting Dalam Menyusun Laporan Keuangan Pada Pemerintahan Desa. Jurnal Akuntansi, Keuangan Dan Audit, 3(1), 36-43. https://doi.org/10.32511/jaka.v3i1.233 